\title{
Effects of Calcium on the Electrocardiogram
}

\author{
Myron Prinzmetal, M.D., Mitsuyoshi Nakashima, M.D., \\ Hiroshi Orshi, M.D., Emir ÖzKan, M.D., Jiro \\ Wakayama, M.D., and James M. Baines, M.D.
}

\begin{abstract}
SUMMARY
Effects of calcium on myocardial cells were investigated in the in situ canine heart. Ninety-three experiments were performed on 28 anesthetized dogs. Solutions of high or low calcium concentrations were perfused into the coronary artery through an artificial coronary circuit. Surface and intracellular electrograms were simultaneously rccorded. The most prominent effect of low calcium was the prolongation of the membrane action potential duration. The most prominent effects of high calcium were a shortening or disappearance of phase 2 and a decrease in the amplitude of phase 2. The mechanism of S-T segment elevation is discussed in association with these findings. These observations show that true S-T segment elevation can be caused by the faster repolarization of cardiac muscle cells in the injured area.
\end{abstract}

\section{Additional Indexing Words :}

High calcium Low calcium Intracellular electrogram Surface electrogram Phase 2 S-T segment displacement

Q-T segment displacement in the clinical electrocardiogram is the most $\omega$ significant change indicative of angina pectoris. In Heberden's angina pectoris there is $S-T$ depression. In the variant form of angina pectoris there is $S-T$ elevation. It is obvious that clarification of the mechanism of S-T segment displacement is important in the interpretation of the clinical electrocardiogram. This is best investigated by comparing the changes in surface electrograms with those in intracellular electrograms. Intracellular electrograms greatly reflect the transmembrane potentials of cardiac cells which are the basic sources of surface electrograms.

This laboratory ${ }^{1 i-5)}$ has previously reported that when a unipolar surface electrogram is recorded from the immediate vicinity of the intracellular electrode, the changes of the ST-T segment correspond to the changes of the repolarization phase.

It is well known that various ions cause changes in intracellular electro-

From the Cedars-Sinai Medical Research Institute and the Division of Medicine, Cedars-Sinai Medical Center; and the Department of Medicine, University of California School of Medicine, Los Angeles.

Received for publication December 17, 1969. 
grams. ${ }^{6)}$ For example, changes in transmembrane gradients of potassium, sodium and other ions cause changes in the amplitude of the membrane resting or action potentials. These are reflected in the surface electrogram as S-T segment displacement. Changes in the concentration of the calcium ion cause considerable changes in the repolarization phase of the intracellular electrogram. ${ }^{6)}$

In the present study, the mechanism of S-T segment displacement was studied by comparing the changes in surface and intracellular electrograms during perfusions of high or low calcium solutions. This work was performed on the in situ canine heart.

\section{METHOD}

Ninety-three experiments were performed on 28 dogs weighing 11 to $25 \mathrm{Kg}$. Each dog was anesthetized with $25 \mathrm{mg} . / \mathrm{Kg}$. intravenous sodium pentobarbital. Opening of the chest and exposure of the heart were performed by methods previously described.? To prevent coagulation of the blood, 50 to $100 \mathrm{mg}$. heparin sodium was injected into the femoral vein. An artificial coronary circuit was made between the left carotid artcry and the anterior descending branch of the left coronary artery (Fig. 1). The recording area was selected on the left ventricular surface which was supplied with blood through the artificial circuit. Two concentric steel rings covered with polyethylene tubing were placed over the recording area. Arms extending from the rings were firmly affixed to the operating table. To minimize movement of the recording area, the outer ring was sutured to the ventricular surface through the epicardium. The inner ring remained unsutured. The parietal peri-

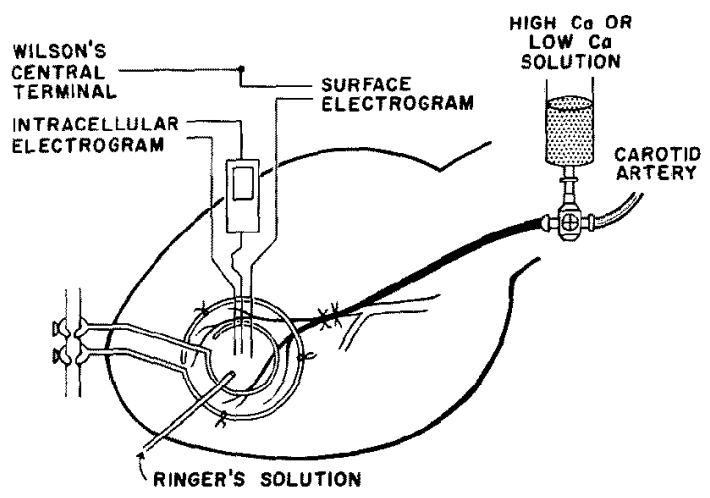

Fig. 1. Diagram of technique used for simultaneous recording of surface and intracellular electrograms. An artificial coronary circuit was made between the anterior descending branch of the left coronary artery and the left carotid artery. High- or low-calcium solutions were perfused into the left coronary artery through the artificial coronary circuit. A unipolar and an intracellular electrogram were simultaneously recorded from the left ventricular region supplied with blood through the artificial circuit. 
cardium within the small ring was removed by dissection. To keep the study area moist and warm, the exposed epicardium was constantly irrigated with Ringer's solution at a thermostatically-controlled temperature of 34 to $35^{\circ} \mathrm{C}$.

Ten ml. of high-calcium or low-calcium solution at a temperature of 34 to $35^{\circ} \mathrm{C}$ was perfused into the artificial coronary circuit at a rate of about $1 \mathrm{ml} / \mathrm{sec}$. This rate is within the normal range of blood flow for the area supplied by the circuit.

Before each experiment, $10 \mathrm{ml}$. of normal blood or $10 \mathrm{ml}$. of Tyrode solution was perfused into the coronary circuit at a rate of about $1 \mathrm{ml} . / \mathrm{sec}$. These perfusions caused no significant changes in the electrograms.

High-calcium solutions were made by adding various amounts of calcium chloride to arterial blood: $2,3,4,8,11$ or 15 times normal. The $\mathrm{pH}$ value of the highcalcium solutions were in normal range. Low-calcium solutions were made by omitting calcium chloride from Tyrode solution. The $\mathrm{pH}$ of the low-calcium solutions was 7.4. The Tyrode solution contained $137.0 \mathrm{mM}$ sodium chloride, $2.7 \mathrm{mM}$ potassium chloride, $11.9 \mathrm{mM}$ sodium bicarbonate, $5.6 \mathrm{mM}$ dextrose, $1.1 \mathrm{mM}$ magnesium chloride, $1.8 \mathrm{mM}$ calcium chloride and $0.4 \mathrm{mM}$ sodium phosphate.

Fifty-five high-calcium and 38 low-calcium experiments were performed.

For about $60 \mathrm{sec}$. from the start of the perfusion, a unipolar surface and an intracellular electrogram were simultaneously recorded. The surface electrode was made of tungsten wire about $0.1 \mathrm{~mm}$. in diameter. The indifferent electrode for the unipolar surface electrogram was Wilson's central terminal. A mounted flexible glass capillary electrode described by Woodbury and Brady ${ }^{8}$ was used to record the intracellular electrogram. Electric resistance of the microclectrode was about 10 megohms. The indifferent electrode for the intracellular electrogram was placed as close as possible to the microelectrode to minimize the extrinsic factor.

Two Grass P6 direct-coupled preamplifiers were used to record the electrograms. The output voltage from each amplifier was introduced into a Tektronix 502 dualbeam cathode-ray oscilloscope and into a Dumont 411 cathode-ray oscilloscope, which served as a monitor. A Sanborn 150 direct-writing electrograph was used to monitor each experiment. Oscilloscopic tracings were photographed with a Grass $\mathrm{C} 4 \mathrm{H}$ kymograph recording camera.

Electrograms were photographically superimposed so that the onsets of extrinsic factors in surface electrograms were identical in time. This was performed for comparison of electrocardiograms recorded before and during the perfusions.

\section{ResUlts}

\section{A. High-calcium experiments}

The effects of calcium persisted for about 1 min. after the perfusion. Changes reverted to pre-infusion patterns within $3 \mathrm{~min}$. Electrographic changes varied in degree and in time of appearance, depcnding upon the $\mathrm{Ca}^{++}$ concentration of the perfusate. Changes began to appear when $3.6 \mathrm{mM}$ calcium chloride was administered. Higher $\mathrm{Ca}^{++}$concentrations produced the following changes.

Surface electrograms: The normally inverted $T$ wave in the control became shallow and progressively decreased in amplitude until the nadir of the $T$ wave 
reached the level of the $T-Q$ segment. Subsequently, the $T$ wave fused into an elevated S-T segment (Fig. 2). The QT interval remained unchanged until the nadir of the $\mathrm{T}$ wave reached the $\mathrm{T}-\mathrm{Q}$ level. There was no change in the rhythm of the heart.

The J-point progressively rose, resulting in a sloping elevation of the

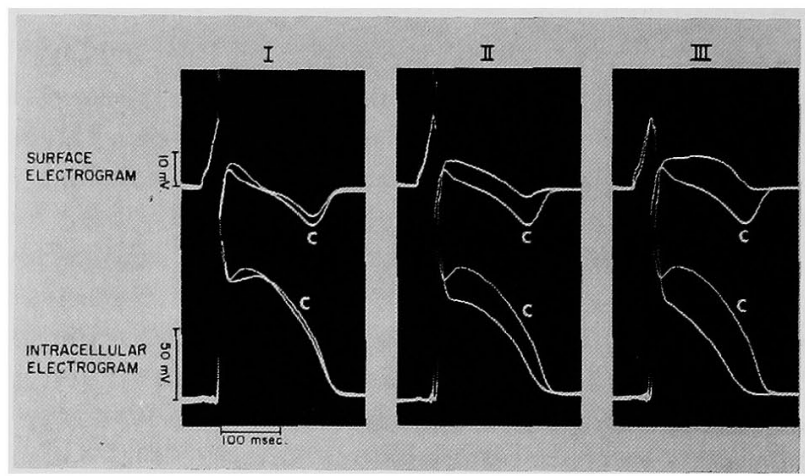

Fig. 2. Surface electrograms (upper tracings) and intracellular electrograms (lower tracings) simultaneously recorded from the left ventricle. Tracings labeled $\mathrm{C}$ were recorded before the high-calcium perfusion. The nonlabeled tracings were recorded during the perfusion. Panel I is the early stage; panel II is the moderate stage: and panel III is the advanced stage of perfusion. The displacement of the ST-T from the control tracing is proportional to the corresponding displacement in the intracellular electrogram. Tracings were photographically superimposed so that the onsets of the QRS complex were identical in time.

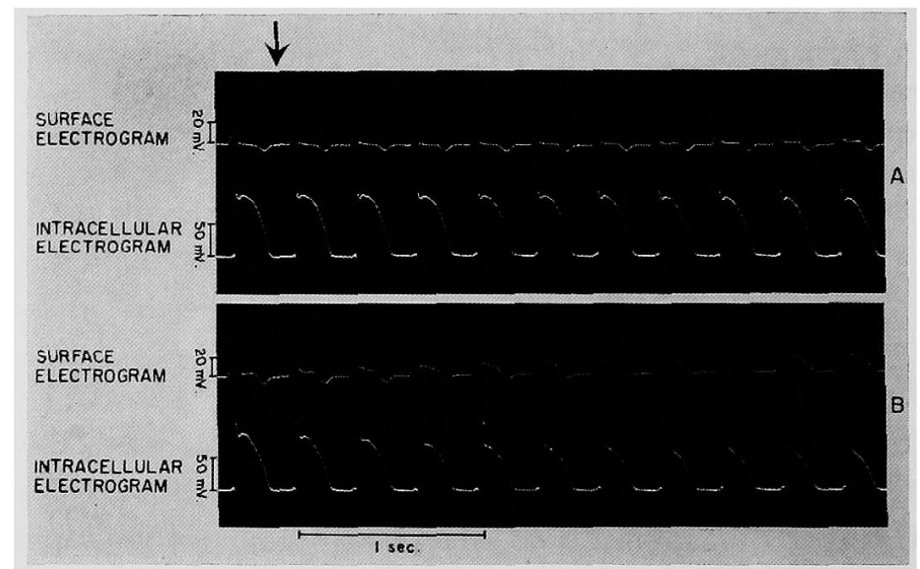

Fig. 3. Continuous simultaneous recordings of surface (upper tracings) and intracellular (lower tracings) electrograms following perfusion of highcalcium solution, $14.4 \mathrm{mM}$. In the surface electrogram the $\mathrm{S}-\mathrm{T}$ segment gradually became displaced upwardly. There is no significant displacement of the T-Q level. In correlation to these changes is the decrease of phase 2 in the intracellular electrogram. 
initial part of the S-T segment (Fig. 2). Subsequently, the terminal part of the S-T segment gradually became upwardly displaced. Finally, the entire S-T segment became elevated. There were no significant changes in the level of the T-Q segment (Figs. 2, 3).

The $\mathrm{R}$ wave gradually increased in amplitude (Fig. 2). The onset of the intrinsic deflection became progressively delayed. The QRS duration became prolonged. There were no significant changes in the rhythm of the heart.

Intracellular electrograms: The convexity of phase 3 slightly decreased (Fig. 2). The amplitude of the membrane action potential (MAP) increased. The dip between phase 1 and phase 2 gradually deepened. As a result of these changes, the spike of phase 1 became prominent (Fig. 2). The amplitude of phase 2 gradually decreased and its duration gradually shortened. The decreasing amplitude of phase 2 caused the spike of phase 1 to become more prominent. The resting level of the MAP showed no significant changes. The duration of the MAP became shortened.

Relationship between surface and intracellular electrographic changes: A constant relationship was observed between surface and intracellular electrographic changes.

Qualitatively, the S-T segment change corresponds to the potential change in phase 2 ; and the change of the $\mathbf{T}$ wave corresponds to the potential change in phase 3 (Fig. 2). The delayed onset of the intrinsic deflection corresponds, qualitatively, to the delayed onset of the MAP. The degree of the elevation of the S-T segment is closely related to the degree of the decrease in the amplitude of phase 2 in the corresponding intracellular electrogram. In general, the greater the decrease in the amplitude of phase 2 , the greater is the elevation of the S-T segment.

The quantitative relationship between changes at the ST-T interval in surface electrograms and the corresponding changes in intracellular electrograms was studied by a method previously described.5) The ST-T interval and the corresponding interval in the intracellular electrogram were divided into sections at each $10 \mathrm{msec}$. interval. The differences of the potentials before and after changes occurred were measured at each interval. These values were plotted on graph-paper. The correlation coefficient $(r)$ was calculated using the following equation ${ }^{51}$ previously formulated in this laboratory.

$$
\left(\mathrm{v}_{2}-\mathrm{v}_{1}\right)=-\mathrm{C}\left(\mathrm{V}_{2}-\mathrm{V}_{1}\right)
$$

In this equation, $\mathrm{v}_{1}$ is the surface potential at any instant of the ST-T interval before changes occurred; $\mathrm{v}_{2}$ is the surface potential at the corresponding instant of a given cardiac cycle during changes; $\mathrm{V}_{1}$ and $\mathrm{V}_{2}$ are the membrane potentials corresponding to $\mathrm{V}_{1}$ and $\mathrm{v}_{2}$ respectively; and $\mathrm{C}$ is a proportionality constant.

As may be seen in Table $\mathrm{I}$, the value of $(r)$ is more than 0.90 in all cases. 


\section{B. Low-calcium experiments}

Surface electrograms. The inverted $\mathrm{T}$ wave seen in the control tracing gradually deepened. The Q-T interval progressively became prolonged. In a few cases the S-T segment became depressed. This was associated with an increase in the amplitude of phase 2 in the intracellular electrogram (Fig. 4).

No changes were observed in the level of the T-Q segment. The $R$ wave gradually decreased in amplitude. The onset of the intrinsic deflection oc-

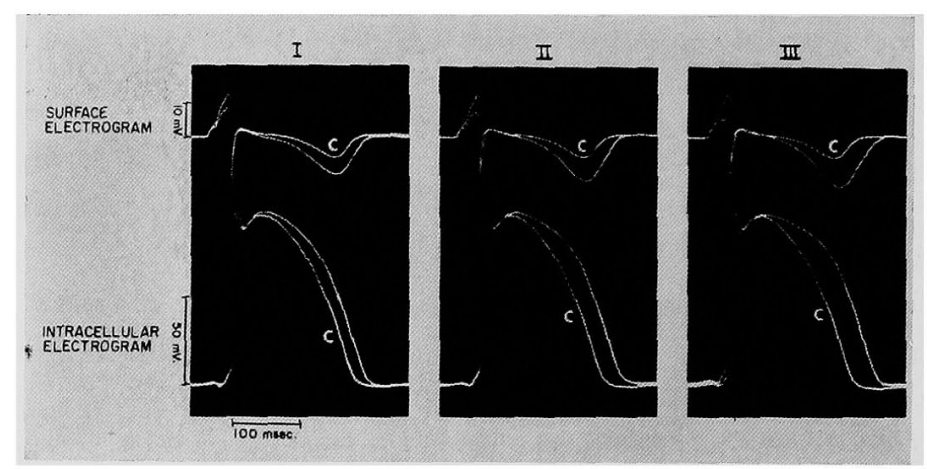

Fig. 4. Low-calcium perfusion. (Same designations as in Fig. 2). The displacement of the ST-T from the control is proportional to the corresponding displacement in the intracellular electrogram. Tracings were photographically superimposed so that the onsets of the QRS complex were identical in time.

Table I. Relationship between Surface and Intracellular

Electrographic Changes Produced by High or

Low Calcium Solutions

\begin{tabular}{c|c||c|c}
\hline \multicolumn{2}{c||}{ High-Calcium } & \multicolumn{2}{c}{ Low-Calcium } \\
\hline \multirow{2}{*}{ Gase No. } & $\begin{array}{c}\text { Correlation } \\
\text { Coefficient } \\
(\mathrm{r})\end{array}$ & Case No. & $\begin{array}{c}\text { Correlation } \\
\text { Coefficient } \\
(\mathrm{r})\end{array}$ \\
\hline 1 & 0.97 & 11 & 0.95 \\
2 & 0.98 & 12 & 0.96 \\
3 & 0.97 & 13 & 0.96 \\
4 & 0.99 & 14 & 0.99 \\
5 & 0.98 & 15 & 0.91 \\
6 & 0.98 & 16 & 0.99 \\
7 & 0.94 & 17 & 0.99 \\
8 & 0.99 & 18 & 0.96 \\
9 & 0.99 & 19 & 0.97 \\
10 & 0.97 & 20 & 0.98
\end{tabular}

See text. 
curred earlier than in control studies (Fig. 4). The QRS duration became slightly shortened. There was no change in the rhythm of the heart.

Intracellular electrograms: The convexity of phase 2 gradually increased, resulting in the prolongation of phase 2 . In 33 cases no discernible changes were observed in phase 3 . In 5 cases the repolarization rate of phase 3 slightly decreased. As a result of these changes, the duration of the MAP became prolonged. The prolongation of phase 2 contributed mainly to a prolongation of the duration of the MAP. In a few cases the amplitude of phase 2 slightly increased. This was accompanied by depression of the S-T segment in the surface electrogram. The resting level of the MAP remained unchanged during the experiment.

Relationship between sufrace and intracellular electrograms: The most distinct relationship between surface and intracellular electrographic changes was observed during the ST-T duration. The potential change of phase 3 in the intracellular electrogram corresponds to the change of the $T$ wave in the surface electrogram (Fig. 4). The potential change of phase 2 corresponds to the change of the $\mathrm{S}-\mathrm{T}$ segment. In each case the value of the correlation coefficient ( $r$ ) is more than 0.90 (Table I).

\section{Discussion}

Effects of calcium on cardiac muscle have been extensively studied. ${ }^{\text {9)-14) }}$ The shortening or disappearance of phase 2 is the most prominent effect of increased calcium concentration on ventricular muscle fiber. The prolongation of the duration of phase 2 is the most promincnt effect of decreased calcium concentration. These effects were also observed in the present study.

There are different opinions regarding the effects of high and low calcium on the amplitude of the membrane resting potential (MRP), and on the duration of the MAP. Some investigators ${ }^{11-13)}$ have reported that high or low concentrations of calcium cause changes in the amplitude of the MRP. Others ${ }^{9,10)}$ found no significant changes in the amplitude of the MRP. In the present study, neither high nor low calcium concentrations caused significant changes in the amplitude of the MRP. Perfusions of low calcium solutions invariably caused prolongation of the duration of the MAP and of the QT interval (Fig. 4).

Qualitatively constant relationships were observed between the changes in surface and intracellular electrograms in the present study. The most prominent was that between changes at the ST-T interval and the changes in the repolarization phase (Figs. 2, 4). Elevation of the S-T segment was associated with a decrease in the amplitude of phase 2, and vice versa (Figs, 2, 
4). In each experiment, the correlation coefficient ( $r$ ) between changes at the ST-T interval and the corresponding changes in the intracellular electrogram was more than 0.90 (Table $\mathbf{I}$ ). There is a quantitatively good linear relationship between the surface and intracellular electrographic changes.

$\mathrm{S}-\mathrm{T}$ elevation is an expression of injury currents which are classified as diastolic and systolic. ${ }^{15)}$ In diastolic injury current, the injured muscle cell membrane supposedly loses the ability to maintain normal polarization. Therefore, the injured area is relatively negative to the uninjured area during the resting stage. This negativity of the injured area causes T-Q level depression. This results in relative $\mathrm{S}-\mathrm{T}$ elevation in surface electrograms recorded from the injured area. In systolic injury current, the injured cell membrane supposedly loses the normal ability to depolarize during activation. As the injured area remains partly polarized after completion of activation, the injured area is relatively positive to uninjured area. Therefore, this persistent polarization in the systolic stage causes true $\mathrm{S}-\mathrm{T}$ elevation in surface electrograms recorded from the injured area. ${ }^{15}$

Many investigators ${ }^{16)-19}$ ) have reported only true $\mathrm{S}-\mathrm{T}$ elevation in the injured area, indicating systolic injury current. Others ${ }^{20)-23)}$ have found only $T-Q$ depression, indicating diastolic injury current. Some investigators ${ }^{24)-28)}$ and this laboratory" observed both T-Q depression and true S-T elevation, indicating the presence of both diastolic and systolic injury currents.

Previously, this laboratory ${ }^{1-5}$ ) observed that the changes of phase 2 correspond to the changes of the S-T segment in surface electrograms recorded from the immediate vicinity of the intracellular electrode. In the present study during perfusions of high-calcium solutions, the S-T segment became greatly elevated without significant depression of the level of the T-Q segment. This $\mathrm{S}-\mathrm{T}$ segment elevation was invariably accompanied by a decrease in the amplitude of phase 2 without significant change in the amplitude of the MRP. This true S-T elevation may be caused by the apparently faster repolarization in the early stage of the repolarization phase, without decrease in the amplitude of the MAP in the injured area. As the injured area is repolarized earlier than the uninjured area in the early stage of the repolarization phase, the injured area becomes relatively positive in comparison to other areas. Therefore, the direct unipolar electrograms recorded from the injured area show true S-T elevation.

Samson and Scher ${ }^{29)}$ reported that relative $\mathrm{S}-\mathrm{T}$ elevation is the result of incomplete polarization. They explained true $\mathrm{S}-\mathrm{T}$ elevation as a manifestation of earlier repolarization of myocardial cells in the injured area.

From the present results it is concluded that true S-T elevation in the surface electrogram can also be caused by the apparently faster repolarization in 
the early stage of repolarization, without hypo-depolarization of myocardial muscle in the injured area.

The nature of S-T depression in the epicardial lead electrogram has been explained as a reciprocal effect of injury current in the subendocardial region. ${ }^{30}$ It has been observed ${ }^{21}$ that $\mathrm{S}-\mathrm{T}$ depression in the surface electrogram is accompanied by an increase in the amplitude of the MRP in the corresponding intracellular electrogram. This has been called "primary" S-T depression, and is caused by hyper-polarization ${ }^{2)}$ of cardiac muscle cells in the injured area.

In the present study during perfusions of low-calcium solutions, there were a few cases in which there was a slight increase in the amplitude of phase 2. These changes correspond to $\mathrm{S}-\mathrm{T}$ depression without significant change in the level of the T-Q segment in the surface electrogram. Therefore, the apparently slower repolarization without hyper-polarization of cardiac muscle cells in the injured area may also contribute to $\mathrm{S}-\mathrm{T}$ segment depression in the surface electrogram.

\section{ACKNOWLEDGEMENT}

The authors thank Mr. Freddie Smith for his participation and assistance in this study.

\section{REFERENCES}

1. Prinzmetal, M., Toyoshima, H., Ekmekci, A., and Nagaya, T. : Clin. Sci. 23 : 489, 1962.

2. Toyoshima, H., Ekmekci, A., Flamm, E, Mizuno, Y., Nagaya, T., Nakayama, R., Yamada, K., and Prinzmetal, M.: Am. J. Cardiol. 13: 498, 1964.

3. Toyoshima, H., Prinzmetal, M., Horiba, M., Kobayashi, T., Mizuno, Y., Nakayama, R., and Yamada, K.: Arch. Int. Med. 115 : 4, 1965.

4. Prinzmetal, M., Toyoshima, H., Nakayama, R., Alvarez, H., Horiba, M., and Kobayashi, T. : New Istanbul Contribution to Clin. Sci. 8 : 10, 1965.

5. Prinzmetal, M., Toyoshima, H., Hattori, M., Horiba, M., Ishikawa, K., Nakayama, R., Nonogawa, A., Özkan, E., Tsuchida, T., and Baines, J. M. : Jap. Heart J. 8 : 67, 1967.

6. Hoffman, B. F, and Cranefield, P. F. : Electrophysiology of the Heart. McGraw-Hill, New York, p. 91, 1960.

7. Prinzmetal, M., Corday, E., Brill, I. C., Oblath, R. W., and Kruger, H. E. : Auricular Arrhythmias. Ciharles C. Thomas, Springfield, Ill., 1952.

8. Woodbury, J. W. and Brady, A.J.: Science 123: 100, 1956.

9. Weidmann, S. : J. Physiol. $129: 568,1955$.

10. Hoffman, B. F. and Suckling, E. E.: Am. J. Physiol. 186 : 317, 1956.

11. Ware, F., Jr., Bennett, A. L., and McIntyre, A. R. : Am. J. Physiol. 198 : 547, 1960.

12. Ware, F.: Am. J. Physiol, 201 : 1113, 1961.

13. Temte, J. V. and Davis, L. D. : Circulat. Res. $20: 32,1967$.

14. Rougier, O., Vassort, G., Garnier, D., Gargouil, Y.-M., and Coraboeuf, E. : C. R. Acad. Sci. Paris 266 : 802, 1968.

15. Ruch, T. C. and Fulton, J. F.: Medical Physiology and Biophysics. W. B. Saunders Co., Philadelphia, p. 618, 1960. 
16. Burdon-Sanderson, J. and Page, F.J. M. : J. Physiol. 2 : 384, 1879.

17. Bayliss, W. M. and Starling, E. H. : Internat. Monat. Anat. Physiol. $9: 256,1892$.

18. Wilson, F. N., Johnston, F. D., and Hill, I. G. W.: Am. Heart J. 10 : 163, 1934.

19. Alzamora-Castro, V., Battilana, G., and Abugattas, R. : Am. Heart J. 54: 254, 1957.

20. Wilson, F. N., Johnston, F. D., Hill, I. G. W., and Grout, G. C. : Proc. Soc. Exp. Biol. Med. $30: 800,1933$.

21. Nahum, L. H., Hamilton, W. F., and Hofr, H. E. : Am. J. Physiol. 139 : $202,1943$.

22. Donoso, E., Wachtel, F, and Grishman, A. : Am. J. Physiol, 189: $219,1957$.

23. Katcher, A. H., Peirce, G., and Sayen, J. J.: Circulat. Res. 8: 29, 1960.

24. Eyster, J. A. E., Meek, W. J., Goldberg, H., and Gilson, W. E. : Am. J. Physiol, 124: 717, 1938.

25. Sugarman, H., Katz, L. N., Sanders, A., and Jochim, K. : Am. J. Physiol. 130 : 130, 1940.

26. Bayley, R. H., LaDue, J. S, and York, D. J. : Am. Heart J. 27 : 164, 1944.

27. Hellerstein, H. K. and Katz, L. N. : Am. Heart J. 36 : 184, 1948.

28. Sodi-Pallares, D.: New Basis of Electrocardiography. C. V. Mosby Co., St. Louis, p. 174, 1956.

29. Samson, W. E. and Scher, A. M.: Circulat. Res. 8: 780, 1960.

30. Harrison, T. R., Adams, R. D., Bennet, I. L., Resnik, W. H., Thorn, G. W., and Wintrobe, M. M.: Principles of Internal Medicine, 5th ed., McGraw-Hill, New York, p. 755, 1966. 